\title{
Política urbana da cidade de Ponta Grossa-PR: a ordenação do solo urbano e a sua relação com os recursos hídricos ${ }^{1}$
}

\author{
Urban policy of the city of Ponta Grossa-PR: the ordering of urban soil and its relationship \\ with water resources
}

\author{
Thais Sanson Sene* \\ Carolina Soares dos Santos ${ }^{* *}$ \\ Sandra Maria Scheffer** \\ Reidy Rolim de Moura**** \\ Lúcia Cortes da Costa ${ }^{* * * * *}$
}

\section{Resumo}

Na cidade de Ponta Grossa a dinâmica entre ordenação territorial e questão ambiental é peculiar, pois conta com $170 \mathrm{~km}$ de arroios no perímetro urbano e grande parte está canalizada, indicando a lógica de desenvolvimento pretendida. Sob a perspectiva crítica dos estudos urbanos, este artigo descreve e analisa o percurso dos arroios da cidade e seu entendimento perante a legislação urbana municipal. Por meio de pesquisa qualitativa, aliada à pesquisa bibliográfica e documental com o uso de legislações e mapas, demonstrou-se que os arroios da cidade não se destacam na legislação urbana e ambiental do município, impactando no desenvolvimento urbano.

Palavras-chave: Urbanização. Ordenação territorial. Questão ambiental. Arroios. Desenvolvimento.

\begin{abstract}
In the city of Ponta Grossa, the dynamics between territorial planning and environmental issues is peculiar, since it has $170 \mathrm{~km}$ of streams in the urban perimeter and much of it is channeled, indicating the desired developmental logic. From a critical perspective of urban studies, this article describes and analyzes the course of the city's streams and their understanding of municipal urban legislation. Through qualitative research, coupled with bibliographical and documentary research with the use of legislation and maps, it has been demonstrated that the city's streams do not stand out in the urban and environmental legislation of the municipality, impacting on urban development.
\end{abstract}

Keywords: Urbanization. Territorial ordering. Environmental issue. Streams. Development.

\footnotetext{
${ }^{1}$ Pesquisa desenvolvida no âmbito dos estudos do Núcleo de Pesquisa de Questão Ambiental, Gênero e Condição de Pobreza do Programa de Pós-Graduação em Ciências Sociais Aplicadas da Universidade Estadual de Ponta Grossa (PPGCSA/UEPG).

* Bacharel em Direito pela Universidade Estadual de Ponta Grossa (UEPG); Mestranda em Ciências Sociais

Aplicadas no programa de Pós Graduação em Ciências Sociais Aplicadas da UEPG.

** Graduanda em Serviço Social pela Universidade Estadual de Ponta Grossa. Aluna PIBIC pela Fundação Araucária

*** Doutora em Gestão Urbana (PUC-PR), Professora do Departamento de Serviço Social da UEPG e do Programa de Pós Graduação em Ciências Sociais Aplicadas UEPG.

**** Doutora em Sociologia Política (UFSC), Professora Adjunta da UEPG.

***** Doutora em Serviço Social (PUC-SP), Professora Associada do Departamento de Serviço Social da UEPG e do Programa de Pós Graduação em Ciências Sociais Aplicadas da UEPG.
} 


\section{Introdução}

A problemática urbana, principalmente quando se refere à esfera de disciplina do uso e ocupação do solo urbano provoca reflexões acerca do processo de produção do espaço urbano. Relacionado a esse processo, um dos grandes problemas enfrentados atualmente na maioria das cidades brasileiras é a degradação ambiental que, pela imperiosa necessidade do sistema capitalista de acumulação, desenvolvimento e crescimento urbano, segue a tônica mercadológica e econômica no trato com o espaço urbano, resultando na flexibilização de normas e direitos ambientais e sociais.

Na dinâmica de ordenação territorial para produção do espaço urbano essa relação entre urbanização, desenvolvimento e desproteção ambiental é visível. A cidade de Ponta Grossa, espaço de desenvolvimento da pesquisa, é altamente urbanizada e possui características físicas e naturais peculiares que impactam no desenvolvimento urbano do município. Por isso, a partir da perspectiva crítica dos estudos urbanos, que considera o espaço como dimensão material da realidade social (LEFEBVRE, 2008). A presente pesquisa pretende analisar de que maneira a legislação urbana de zoneamento, uso e ocupação do solo da cidade de Ponta Grossa-PR compreende a questão ambiental, notadamente considerando o fato de o município contar com $170 \mathrm{~km}$ de arroios no perímetro urbano (ROGALSKI, 2011).

Para elucidação da problemática exposta, objetiva-se verificar de que forma e em que medida a malha hídrica do município de Ponta Grossa é compreendida nos processos de produção do espaço urbano, ou seja, se e como a política urbana municipal, por meio dos instrumentos legais que disciplinam o zoneamento, uso e a ocupação do solo, está ou não aliada à preservação dos arroios urbanos.

Para tanto, estabeleceu-se como objetivo geral do presente artigo analisar de que forma a legislação de zoneamento, uso e ocupação do solo do município de Ponta Grossa-PR incorpora e compreende a questão ambiental relacionada aos recursos hídricos neste espaço. E, especificamente, compreender o processo de urbanização da cidade de Ponta Grossa-PR e produção do espaço urbano, com ênfase no tratamento conferido aos arroios localizados no perímetro urbano, além de identificar na legislação municipal pertinente à definição de zoneamento, uso e ocupação do solo (Lei municipal no 6.329/1999), suas implicações na questão ambiental referente aos arroios da cidade, na perspectiva posta pelo ordenamento jurídico brasileiro pós Constituição Federal de 1988. 
A análise legislativa justifica-se porque o Estado é o responsável pela formulação, gestão e execução de políticas públicas e, no que atine às questões urbanas, compete ao Município (art. 30, VIII, CF/88) promover o adequado ordenamento territorial, mediante planejamento e controle do uso, parcelamento e ocupação do solo urbano pelos diferentes agentes sociais, gerindo as relações para dinamizar o crescimento e o desenvolvimento das cidades por meio de políticas públicas. Ademais, segundo o art. 23, VI, da CF/88, ao Município cabe promover a defesa do meio ambiente, legislando de forma complementar à legislação federal e estadual (BRASIL, 1988).

Assim, considerando as características naturais geográficas do município de Ponta Grossa-PR, ao relacionar a análise do processo de urbanização da cidade com os processos legais de ordenação territorial pretende-se verificar e entender como os arroios localizados no perímetro urbano são abrangidos nesta dinâmica e, dessa maneira, compreender a lógica aplicada ao desenvolvimento urbano da cidade de Ponta Grossa-PR quanto ao aproveitamento e proteção dos arroios urbanos sob a perspectiva da legislação municipal.

Portanto, para o desenvolvimento da pesquisa o percurso metodológico tem início a partir de seu recorte espacial, a cidade de Ponta Grossa-PR, porque possui uma política pública urbana de ordenação territorial que conjectura-se marcada por uma lógica mercadológica que não compreende à proteção dos arroios da cidade. Para tanto, utiliza-se o método dialético como método de abordagem, partindo-se das contradições entre a ordenação territorial e a preservação, ou não, dos arroios da cidade, para cumprir o objetivo geral apresentado.

Como instrumentos de pesquisa, utilizam-se as pesquisas bibliográfica e documental, por meio das quais se buscou analisar e cumprir os objetivos específicos definidos. Para isto, foram identificadas e mobilizadas como fontes as legislações federais e municipais relacionadas à definição de zoneamento, uso e ocupação do solo e proteção ambiental, além de mapas de hidrografia e de zoneamento do município de Ponta Grossa-PR.

O processo de análise, por sua vez, implicou na organização do conteúdo coletado e na exploração das possibilidades teóricas deste de forma a apresentar um diagnóstico da cidade de Ponta Grossa, sua estrutura legislativa de zoneamento, uso e ocupação do solo, bem como as características físico-geográficas do município, especialmente quanto à malha hídrica que permeia a cidade. Após, o enfoque foi para o estabelecimento de articulações entre os elementos empíricos identificados no diagnóstico acima mencionado e no suporte teórico construído, a fim de identificar teoricamente o enquadramento dos achados da pesquisa, 
principalmente quanto às concepções de políticas públicas. Por último, concentrou-se na exposição das reflexões de forma a dar conta da explicação das relações internas e externas que o objeto revela (MINAYO apud GOMES, 1998), confrontando-se o diagnóstico municipal de zoneamento e questão ambiental com a teoria construída.

Como finalidade desta análise estabeleceu-se responder o objetivo geral formulado, qual seja, o de analisar de que maneira a legislação de zoneamento, uso e ocupação do solo do município de Ponta Grossa-PR incorpora e compreende a questão ambiental relacionada aos recursos hídricos neste espaço, notadamente quanto aos arroios urbanos, bem como debater as contradições entre a legislação de zoneamento, uso e ocupação do solo de Ponta Grossa-PR e a preservação ambiental dos arroios da cidade, demonstrando as deficiências desta última e propondo, ainda que se reconheçam as limitações da pesquisa, reflexões críticas acerca da forma como os recursos hídricos da cidade são compreendidos nas políticas de ordenamento territorial e como isto impacta no desenvolvimento urbano municipal.

\section{O Processo de Produção do Espaço Urbano e Questão Ambiental: Reflexões Iniciais}

O processo de produção do espaço está intimamente relacionado ao processo histórico, social e econômico de uma sociedade, é o lugar onde se produz e reproduz o modelo de produção da sociedade. O espaço da cidade cada vez mais é apropriado como espaço produtivo. A forma com que a cidade organiza as dinâmicas de produção e circulação de bens, pessoas e ideias; a maneira pela qual os diversos atores sociais apropriam-se do espaço urbano refletindo a desigualdade na distribuição de benfeitorias coletivas é resultado de processos econômicos e disputas políticas entre os diferentes setores da sociedade (SANTOS, 2012).

Assim, a ordenação do uso do espaço urbano correlaciona formas espaciais e relações sociais que são produzidas e reproduzidas historicamente no âmbito de um modo de produção específico, revelando a sistemática da interação entre os diversos agentes da sociedade na produção do espaço urbano.

A partir dessa concepção relacional Lefebvre (2008) permeia o processo de produção do espaço. Compreendendo o espaço como o lugar de reprodução das relações sociais de produção, avança na apreensão da relação Estado-sociedade ao entender que o espaço é dinâmico, palco de lutas sociais, sendo múltiplo, heterogêneo e contraditório, justamente, porque é social e historicamente produzido. 
Sendo, portanto, o espaço um produto social, Lefebvre (2008) propõe a teoria socioespacial que o compreende como fator fundamentalmente conectado à realidade social, isto é, o espaço não existe sozinho, é produzido; se perfaz da relação do homem com o espaço, numa dinâmica mútua onde homem e sociedade se influenciam e produzem o espaço, donde se extrai que "não há realidade social inespacial; qualquer realidade social é, por definição, espacial" (MONTE-MÓR, 2006, p. 1-2)

Nesse sentido, a cidade é um lugar privilegiado para observação dos fenômenos sociais e como forma de organização espacial humana, é mais do que um reflexo da sociedade. É sua própria estruturação social, reproduzida num espaço relativamente limitado, no qual se constituem as sociedades e emergem as contradições da reprodução da vida, afirmando-se os contornos da distinção das classes sociais. É o lugar de realização onde se operam as vivências e é, portanto, um espaço de luta em busca do processo de transformação social. Nesse sentido, David Harvey (1996) compreende a urbanização como um conjunto de processos sociais que se dão no espaço e no tempo, atuando como instrumentos de reprodução do capital.

Uma característica da urbanização brasileira é o desenvolvimento em áreas de preservação permanente, revelando um cenário complexo às questões habitacionais e ambientais que se encontram entre o mercado fundiário e imobiliário. Com este tensionamento, há necessidade de integrar habitação e meio ambiente visando harmonizar o desenvolvimento urbano e as limitações ambientais de maneira que se possa promover moradias dignas protegendo os recursos naturais.

Já a questão ambiental decorre da transformação da consciência da humanidade em relação à utilização desenfreada e desequilibrada dos recursos naturais, que tem como foco a produção cada vez maior, sem dimensionar os possíveis danos que podem ser causados ao meio ambiente. A questão ambiental tem um caráter social e político, e pode ser entendida como o modo pelo qual a sociedade se relaciona com o meio em que vive (SAUER; RIBEIRO, 2012).

A relação entre os sujeitos com o meio em que vivem tem se tornado cada vez mais complexa, o crescimento industrial e demográfico são simultâneos à degradação do meio ambiente, que vem se mostrando cada vez mais devastadora. A degradação ambiental das bacias hidrográficas urbanas está relacionada ao processo histórico de urbanização dos municípios bem como a falta de políticas públicas associadas à ausência de novas estratégias 
de intervenção e planejamento adequado dos atores sociais e políticos que utilizam e constroem o espaço urbano. E a sua importância há que ser preservada, pois como afirma Carvalho (2004, p. 36) “A bacia hidrográfica como unidade de estudos pode ser considerada como a expressão, em diversas escalas, da interação da sociedade e natureza na produção do espaço".

Nesse contexto, ingressando na esfera de análise de políticas públicas e papel do Estado, parte-se da concepção de que políticas públicas configuram ações do Estado para implementação de determinados objetivos decorrentes das demandas sociais. Assumem uma visão holística, na perspectiva que o todo é mais importante do que a soma das partes dos indivíduos, instituições, interações, ideologias e interesses. É um campo do conhecimento que busca colocar o governo em ação, analisando essa ação e quando necessário propondo alterações no rumo delas (SOUZA, 2006). Com essa perspectiva, a autora afirma que a essência da política pública é o embate entre ideias e interesses, por isto é um campo multidisciplinar cujas ações repercutem na economia e nas sociedades. Nessa perspectiva Souza (2006) aponta os elementos principais que configuram as políticas públicas:

\begin{abstract}
A política pública permite distinguir entre o que o governo pretende fazer e o que, de fato, faz. A política pública envolve vários atores e níveis de decisão, embora seja materializada através dos governos, e não necessariamente se restringe a participantes formais, já que os informais são também importantes. A política pública é abrangente e não se limita a leis e regras. A política pública é uma ação intencional, com objetivos a serem alcançados. A política pública, embora tenha impactos no curto prazo, é uma política de longo prazo. A política pública envolve processos subsequentes após sua decisão e proposição, ou seja, implica também implementação, execução e avaliação (SOUZA, 2006, p. 36-37).
\end{abstract}

No mesmo sentido, Giovanni (2009, p. 4-5) “compreende a política pública como uma forma contemporânea de exercício do poder nas sociedades democráticas", resultante de complexas interações entre o Estado e a sociedade, tanto no campo social quanto econômico, das quais emergem as problemáticas sociais e sobre as quais o Estado deve, então, desenvolver as formas, os conteúdos e a modalidade de intervenção estatal. Ao entender a política pública como forma política o autor traz para o conceito a perspectiva de análise das relações de poder afirmando que "no campo político, as políticas públicas, não são uma forma única ou exclusiva, mas convivem com formas vigentes das diferentes sociedades" (GIOVANNI, 2009, p. 6). 
Por sua vez, Kauchakje e Scheffer (2017) ressaltam que a política pública consiste no "produto da tomada de decisão governamental [...] articulada ao processo decisório" (KAUCHAKJE; SCHEFFER, 2017, p. 19) e, assim, afirmam que a política pública:

Faz parte de processos determinantes políticos (internos e internacionais), econômicos, culturais, legais e institucionais, que, por sua vez, se desenrolam conforme trajetórias históricas e relações de força. Enfim, a tomada de decisão é um processo e um resultado referido ao poder político (KAUCHAKJE; SCHEFFER, 2017, p. 20).

Com fundamento nessas concepções, partindo-se da ideia de que políticas públicas configuram ações do Estado para implementação de determinados objetivos decorrentes das demandas sociais, pode-se buscar nos direitos fundamentais de segunda geração - os direitos sociais - o próprio fundamento de existência das políticas públicas, ao passo em que exigem do Estado uma prestação, uma obrigação positiva, um fazer. ${ }^{2}$

Desse modo vê-se que o Estado tem a incumbência de elaborar e aplicar as políticas públicas, buscando solucionar questões sociais. No que atine às questões urbanas, cabe então ao Estado a formulação e aplicação de políticas públicas relacionadas à ordenação e ocupação do espaço pelos diferentes agentes sociais.

Assim, de modo a planejar e organizar as relações que compõem a cidade, desenvolvendo sua função social e garantindo o bem-estar dos seus habitantes, com o advento da Constituição Federal de 1988 (CF/88), a política urbana ganhou novos contornos (artigo 182 e 183) e regulamentação específica com o Estatuto da Cidade (Lei № 10.257/2001), impondo ao município - elevado à qualidade de ente federativo - o dever de execução das diretrizes necessárias à concretização de tais objetivos por meio da elaboração do plano diretor, o instrumento básico da política de desenvolvimento e expansão urbana, e obrigatório para as cidades brasileiras com mais de 20 mil habitantes $^{3}$.

Aliando questão urbana e ambiental na legislação, extrai-se que o pleno desenvolvimento das funções sociais da cidade perpassa pela garantia e proteção do meio ambiente. Tanto que algumas das diretrizes gerais do Estatuto da Cidade dispõem

\footnotetext{
2 "Todas as declarações recentes dos direitos do homem compreendem, além dos direitos individuais tradicionais, que consistem em liberdades, também os chamados direitos sociais, que consistem em poderes. Os primeiros exigem da parte dos outros (incluídos aqui os órgãos públicos) obrigações puramente negativas, que implicam abstenção de determinados comportamentos; os segundos só podem ser realizados se for imposto a outros (incluídos aqui os órgãos públicos) um certo número de obrigações positivas" (BOBBIO, 2004, p. 21).

${ }^{3}$ No estado do Paraná, com a promulgação da Lei estadual no 15.229/2006, todos os municípios do estado passaram a ser obrigados a apresentarem seus planos diretores como condição de financiamento estadual.
} 
expressamente que a política urbana deverá guiar-se pela proteção, preservação e recuperação do meio ambiente, pela garantia do direito a cidades sustentáveis para as presentes e futuras gerações, pela ordenação e controle do uso do solo de forma a evitar a degradação e poluição ambiental, além de diversas outras disposições que culminam na proteção global do meio ambiente no espaço urbano (art. 2으, Lei 10.257/2001). No mesmo sentido tem-se a Política Nacional do Meio Ambiente (Lei no 6938/81) e a própria Constituição Federal.

Estabelecido o quadro teórico e legislativo geral que permeia a presente análise, passa-se à caracterização dos aspectos legais urbanos e ambientais da cidade de Ponta GrossaPR.

\section{O Município de Ponta Grossa: Legislação Urbana e Aspectos Ambientais}

Para compreender a análise sobre o município de Ponta Grossa, é importante caracterizá-lo na esfera nacional e regional. Assim, o município de Ponta Grossa-PR está situado na região dos Campos Gerais, no segundo planalto paranaense, com área territorial de $2.054,732 \mathrm{~km}^{2}$. No que se refere à densidade demográfica possui taxa de $150,72 \mathrm{hab} . / \mathrm{km}^{2}$, ocupando a primeira posição na microrregião, a 20a no estado paranaense e a 466a no país (IBGE, 2010).

Quanto aos aspectos populacionais, conta com uma população censitária total de 311.611 pessoas, sendo o 4ำ município de maior população do estado do Paraná, conforme o Censo IBGE de 2010. Atualmente, estima-se que conta com 348.043 pessoas (IBGE, 2018)4 . Índice de Desenvolvimento Humano Municipal - IDHM, Ponta Grossa-PR, conforme o último censo demográfico de 2010 é de 0,763, o que classifica o município com uma faixa de desenvolvimento humano alto (IDHM entre 0,700 e 0,799).

Caracteriza-se por ser um município com uma base diversificada de produção. Com relação às atividades econômicas desenvolvidas, se destaca pela área de serviços tendo forte participação na indústria e na agropecuária. Economicamente, segundo o IBGE (2010), o município de Ponta Grossa-PR possui PIB per capita de $\mathrm{R} \$ 38.035,14$. Com essa estrutura cumpre destacar que o município de Ponta Grossa-PR, com relação à influência que exerce

\footnotetext{
${ }^{4}$ A população estimada foi levantada pelo IBGE, Diretoria de Pesquisas, Coordenação de População e Indicadores Sociais na pesquisa: Estimativas da população residente com data de referência 1o de julho de 2018.
} 
sobre as demais cidades da região, é classificado pelo REGIC - Região de Influência das cidades como "Capital Regional C", significando que se constitui em uma "área de influência de âmbito regional, sendo referida como destino, para um conjunto de atividades, por grande número de municípios" (IBGE, 2008).

Sobre o processo de urbanização da cidade, Ponta Grossa-PR se constitui como uma cidade altamente urbanizada com taxa de 97,79\% (IBGE, 2010), processo esse que historicamente sempre foi marcante, acentuando-se a partir da década de $1890 \mathrm{com}$ a articulação da cidade ao sistema ferroviário nacional. O que conferiu a Ponta Grossa a qualidade de importante entroncamento ferroviário e entreposto comercial do sul do país, conectando-a a outras importantes cidades do país e criando a estrutura para a expansão do desenvolvimento urbano (CHAVES et al., 2001).

Neste contexto, o município passou a atrair cada vez mais fluxos populacionais para a área urbana, de forma que no início do século XX já apresentava a maior parcela de sua população residindo na cidade e trabalhando em atividades essencialmente urbanas (PAULA, 1993), o que demandou o aumento no consumo de água da população e na necessidade de criação de um sistema de abastecimento, impactando diretamente no processo de urbanização e nos arroios que percorrem toda a cidade. Isto porque, atualmente, o que se observa em Ponta Grossa é que a maioria dos arroios possuem moradores em suas margens ou estão canalizados (SILVA, 2017).

Adentrando nos aspectos hidrográficos do município que o particularizam, Ponta Grossa está inserida em duas importantes bacias hidrográficas do estado do Paraná (Tibagi $81 \%$ de seu território e Ribeira 19\%). A área central da cidade é nascente de quatro arroios, Arroio de Olarias, Pilão de Pedra, Lajeado Grande e Arroio da Ronda.

Relacionando tais aspectos com a urbanização da cidade, constata-se íntima relação entre os arroios e a urbanização de Ponta Grossa, cujo processo ocorreu a partir de um eixo central, de onde alastrou-se uma rede hidrográfica radial (MEDEIROS; MELO, 2001), justamente pelo fato de a cidade ser banhada pelas bacias hidrográficas dos rios Ribeira e Tibagi, tornando-se o centro por onde se expandem os rios que percorrem a paisagem e formam uma drenagem radial.

Este aspecto hidrográfico que marca a cidade de Ponta Grossa é evidenciado no perímetro urbano pela presença de $170 \mathrm{~km}$ de arroios que percorrem a área central, bairros e vilas do município (ROGALSKI, 2011), o que se visualiza nos mapas a seguir que situam o 
município na rede de bacias hidrográficas do estado do Paraná (figura 1) e demonstram a rede de bacias e sub-bacias que perpassam o território do município (figura 2):

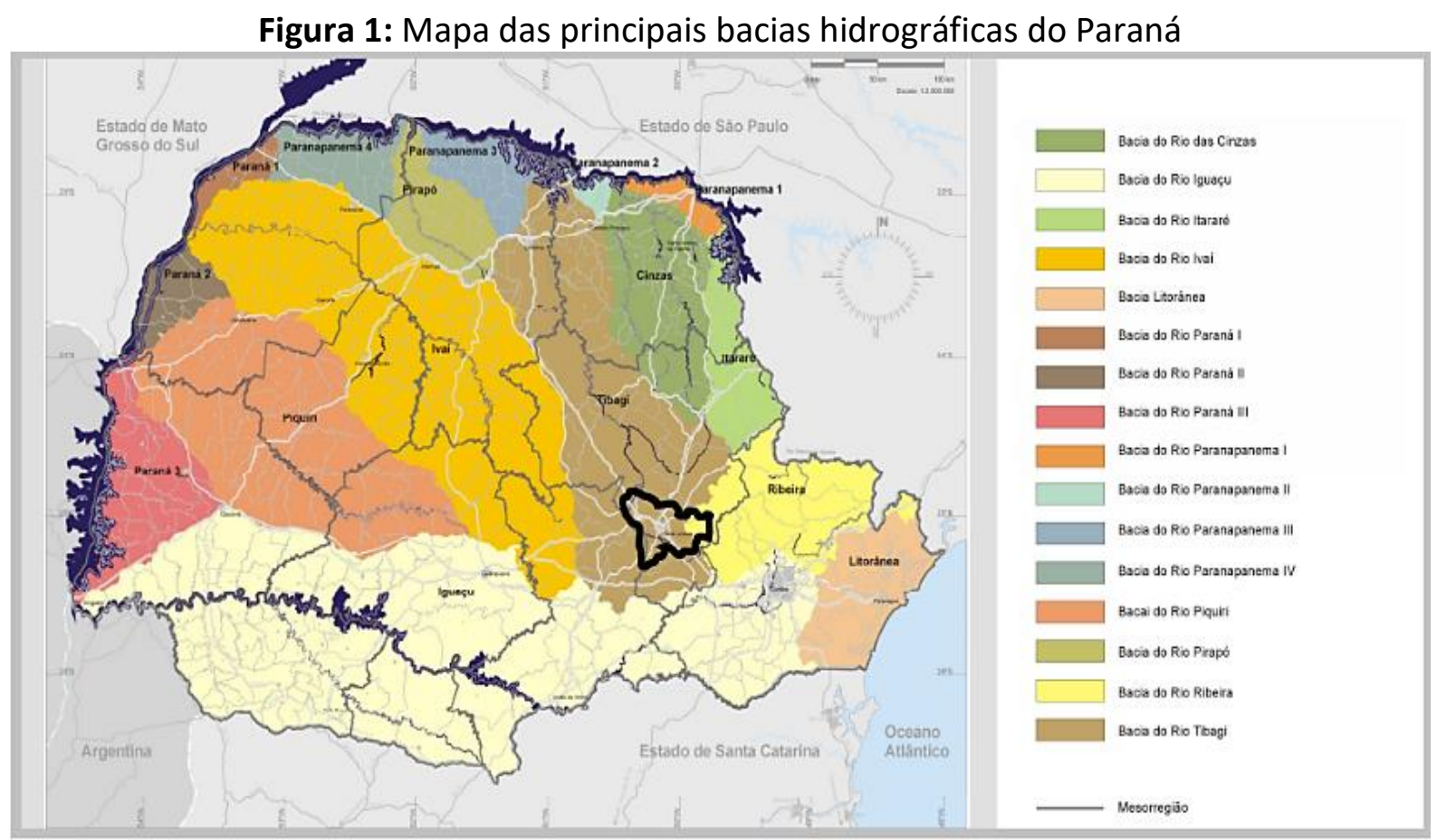

Fonte: Ponta Grossa (2016c).

Figura 2: Bacias e Sub-Bacias da cidade de Ponta Grossa-PR
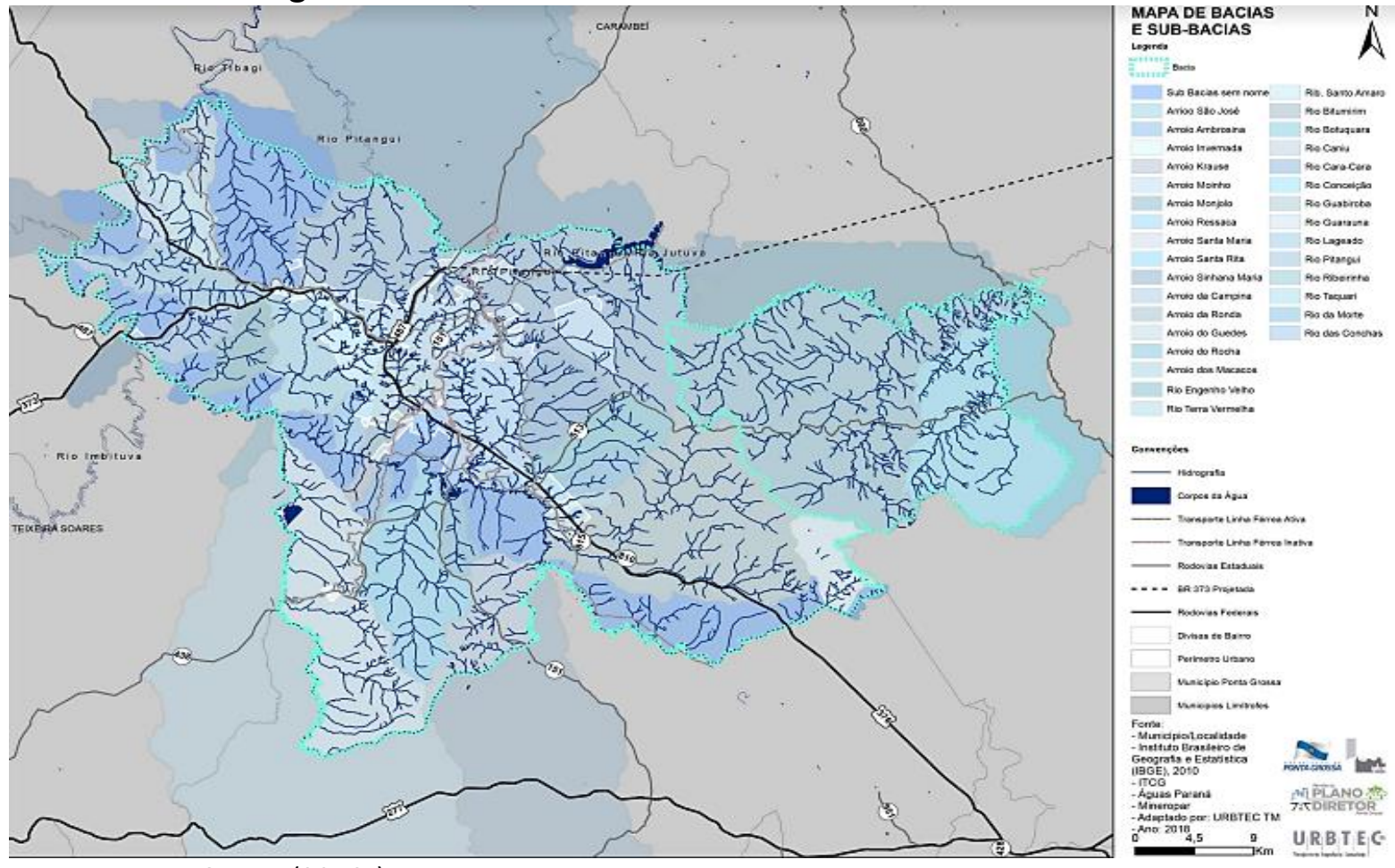

Fonte: Ponta Grossa (2016c). 
Das imagens acima, especialmente a figura 2 das bacias e sub-bacias que transpõem o território de Ponta Grossa-PR, é possível compreender porque o processo de urbanização da cidade se deu de forma radial, porquanto a necessidade de abastecimento de água conduziu as ocupações urbanas e moldou o espaço urbano de Ponta Grossa-PR.

Atrelando esses aspectos ambientais e geográficos com a produção do espaço urbano e considerando o papel do Estado na seara das políticas públicas, se pode afirmar que a atuação do Estado por meio da legislação de definição de zoneamento, influencia a distribuição das atividades e dos investimentos em infraestrutura no território (SANTOS, 2012). Nesse sentido, justamente em virtude das características peculiares da cidade de Ponta Grossa-PR, extrai-se a importância da análise da dinâmica da legislação municipal de ordenação do solo urbano, a Lei no 6329/1999, e suas constantes alterações que modificam o espaço urbano, além da legislação ambiental da cidade, cujas transformações impactam nos cursos dos arroios da cidade. Isso para se perceber como os arroios estão compreendidos na legislação urbana, se o aspecto do desenvolvimento mercadológico se impõe à manutenção e preservação dos arroios da cidade.

Assim, a estrutura da legislação urbana municipal possui marcos legais relevantes, merecendo destaque neste momento os seguintes documentos: a) Lei $n$ o 6.329/1999: que consolida e atualiza a legislação que dispõe sobre o zoneamento de uso e ocupação do solo das áreas urbanas do município de Ponta Grossa-PR; b) Lei Municipal no 6.180/1999: que cria o Instituto de Pesquisa e Planejamento Urbano de Ponta Grossa - IPLAN; c) Lei no 8.663/2006: que aprova o plano diretor do município de Ponta Grossa-PR para o decênio 2006/2016; d) Lei no 12.223/2015 e Decreto no 11.319/2016: que instituem o Conselho Municipal da Cidade; e) Lei no 12.447/2016 e Decreto no 12.951/2017: que dispõem sobre o Estudo de Impacto de Vizinhança; e f) Lei no 12.821/2017: que institui o Fundo Municipal de Desenvolvimento Urbano (PONTA GROSSA, 1999b, 1999a, 2006, 2015, 2016a, 2016b, 2017a, 2017b).

O sistema legal de proteção ambiental do município é estruturado conforme o designado na Lei no 11.233/2012 (PONTA GROSSA, 2012), que dispõe sobre a Política Municipal de Meio Ambiente e outras providências, incluindo a previsão do Conselho Municipal de Meio Ambiente (COMDEMA), órgão de assessoramento ao Poder Executivo Municipal e deliberativo no âmbito de sua competência sobre as questões ambientais. 
Destacadamente, sobre a temática desta pesquisa importa mencionar que a Lei municipal no 6.329/1999, de zoneamento, uso e ocupação do solo, ainda em vigor, organiza o perímetro urbano da cidade em diversas zonas com usos variados, quais sejam: Zona Central (ZC); Zona Polo (Z Polo); Zona Eixo Ponta Grossa (ZEPG); Zona Comercial (ZCOM); Corredor Comercial (CC); Zona de Serviços 1 e 2 (ZS1 e ZS2); Zona Industrial (ZI); Zona Residencial 1, 2, 3, 4 e 5 e Zona Especial de Interesse Social (ZR1, ZR2, ZR 3, ZR4, ZR5 e ZEIS); Zona Verde Especial I; Zona Verde Especial II (art. 5, Lei 6329/99).

Ocorre que, ao longo dos anos a referida lei sofreu mais de uma centena de emendas, sendo 120 alterações entre 1999 a 2016 (SCHEFFER, 2017), notadamente, no zoneamento comercial e residencial, as quais reconfiguraram o espaço urbano da cidade de Ponta Grossa$\mathrm{PR}$, criando novas áreas, expandindo e verticalizando a cidade, e dispondo sobre diferentes usos do solo.

Neste universo há 10 disposições expressas que compreendem os arroios, alterando ruas específicas para áreas comerciais ou residenciais ${ }^{5}$. Além destas, extrai-se da legislação municipal uma série de decretos do poder executivo desapropriando áreas urbanas para construção de galerias pluviais, obras de canalização e recuperação de arroio ${ }^{6}$.

Por outro lado, embora a existência de legislação na esfera federal e estadual, quando se volta a análise para a legislação ambiental municipal, notadamente na política municipal de meio ambiente (Lei no 11.233/2012), não se vislumbra a mesma intensidade de proteção aos arroios urbanos. O que é grave, já que o município possui 170 km de arroios em seu perímetro urbano.

A fragilidade da legislação municipal mencionada fica destacada quando se analisam as disposições referentes à proteção ambiental do solo (artigo 19 e seguintes) na política municipal de meio ambiente. Por estas o uso do solo urbano deve se dar conforme as disposições da lei de zoneamento, uso e ocupação do solo urbano (Lei no 6.329/1999), observando sempre as características geofísicas, morfológicas e ambientais do solo, sob pena de punição e reparo do dano causado. Nesta esteira, aliando instrumentos urbanísticos de

\footnotetext{
${ }^{5}$ As alterações legislativas compreendem áreas que abrangem os arroios da prancha, da universidade e do padre, principalmente. Tais áreas tiveram seus zoneamentos reclassificados para zonas comerciais ou residenciais (2, 3 e 4), nas quais, ao menos em tese, permite-se edificação.

${ }^{6}$ Existem aproximadamente 20 decretos do poder executivo municipal cujo objetivo é a desapropriação de lotes urbanos para fins de construção de galerias de águas pluviais, canalização e recuperação de arroios desta cidade, especialmente para construção de obras públicas, a exemplo do Parque de Olarias (Decretos $\mathrm{n}$ 은 $10.205 / 2015 ; 10.272 / 2015 ; 10.460 / 2015)$.
} 
ordenação do território e proteção ambiental, o §50 do artigo 20 da política municipal ambiental (Lei no 11.233/2012) condiciona as restrições e limitações ambientais a serem impostas aos empreendimentos urbanos às previsões do Zoneamento Ambiental Municipal, que, embora previsto como uma das leis que compõem o plano diretor atual (art. 5ㅇ, XI, Lei Municipal no 8.663/2006), nunca foi editado e regulamentado, deixando esta sensível questão do município carente de melhor e mais efetiva proteção.

Da política municipal de meio ambiente apenas os artigos 39 e 44 dispõem expressamente sobre a necessidade de medidas de proteção aos arroios pelo empreendedor quando da execução de loteamentos urbanos, o que demonstra a fragilidade da legislação municipal protetiva dos arroios frente à legislação urbana de zoneamento, uso e ocupação do solo. E, considerando que o espaço na sociedade capitalista torna-se uma mercadoria cada vez mais valiosa (SANTOS, 1991), na medida em que a atuação estatal por meio da legislação se mostra frágil e não há estímulo à preservação dos arroios em seus cursos naturais, a faceta especulativa e mercadológica muitas vezes acaba por se sobressair, alimentada pela inércia e inoperância estatal.

Essa relação fica mais visível no mapa de zoneamento urbano da cidade de Ponta Grossa, onde estão explicitadas as zonas urbanas (art. 5, Lei 6.329/99) e os cursos d'água:

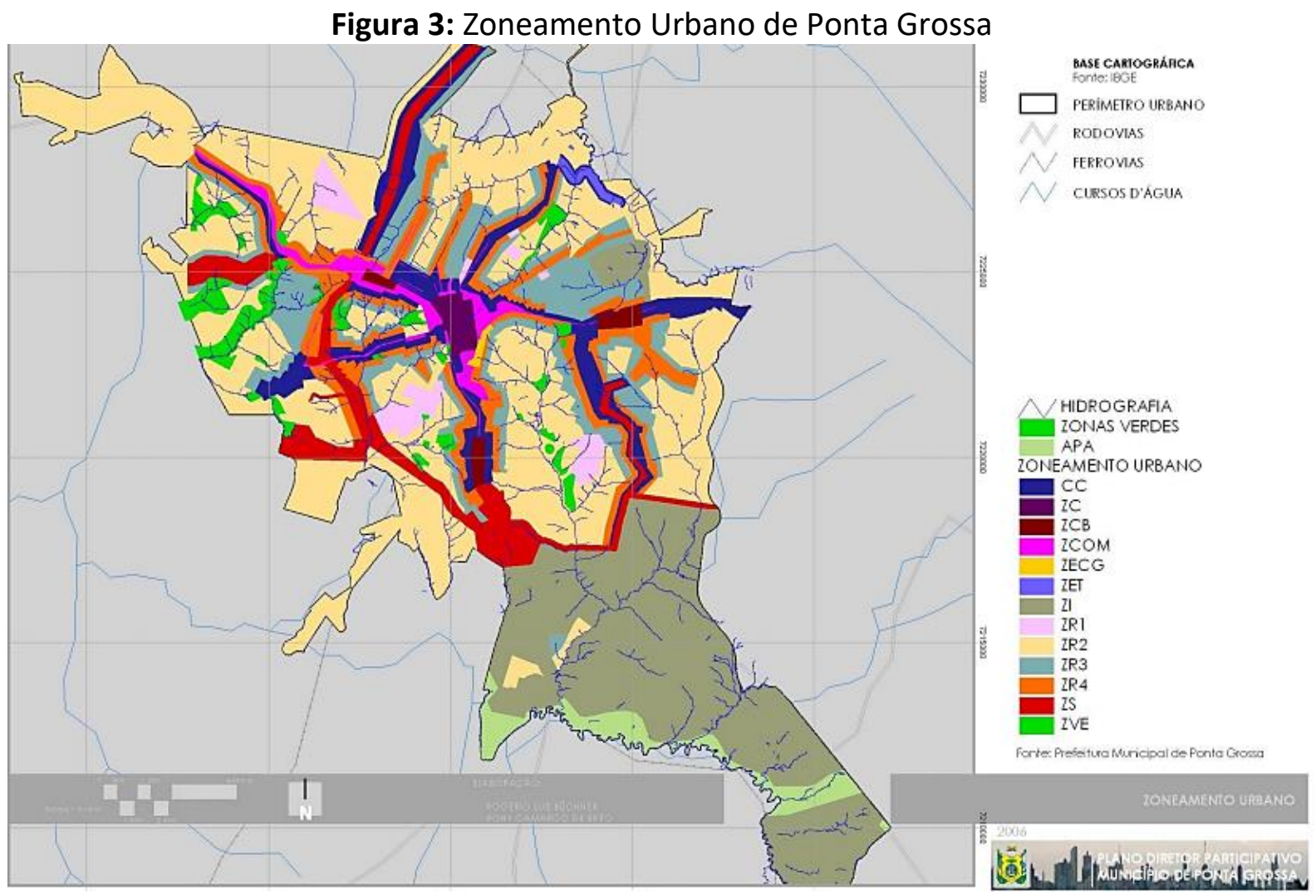

Fonte: Ponta Grossa (2016c). 
Da figura se destaca a delimitação das zonas residenciais (1,2,3 e 4), além da comercial, as quais sofrem constantes alterações e pelas quais perpassam - canalizados (SILVA, 2017) - as centenas de quilômetros de arroios que atravessam o perímetro urbano da cidade de Ponta Grossa-PR.

Destes dois movimentos legislativos mencionados se observa que a peculiaridade da malha hídrica do município de Ponta Grossa-PR não é integralmente contemplada pela legislação municipal, pois na medida em que os instrumentos de regulamentação e proteção ambiental ainda são frágeis ou inexistentes, a legislação urbana de ordenação territorial e a expedição de decretos que impactam diretamente no curso dos arroios municipais segue em intensa atividade, demonstrando o desequilíbrio legal entre as políticas urbana e ambiental da cidade de Ponta Grossa-PR.

\section{Resultados e Conclusões}

A integração da proteção ambiental com a ordenação do espaço urbano é uma questão social, econômica e política permeada por influências e contradições que afetam a sociedade e o Estado. Com a expansão urbana crescente se faz necessário pensar em como os recursos naturais das cidades são pensados e amparados, hoje infelizmente na maior parte dos lugares, esses recursos são utilizados de forma desequilibrada. Como um reflexo do desenvolvimento capitalista a humanidade aprofunda a cada dia sua trajetória de destruição da natureza, sem pensar nas consequências futuras ou nos reflexos que o mau uso destes recursos pode acarretar.

O município de Ponta Grossa possui a maior parte de sua população em área urbana e nesta mesma área urbana conta com $170 \mathrm{~km}$ de arroios que nutrem a cidade. Contudo, da legislação observada se constata que a proteção dedicada aos arroios é frágil e não obsta o avanço das perspectivas mercadológicas e especulativas de desenvolvimento, uma vez que a legislação urbana de zoneamento, uso e ocupação do solo é intensamente alterada, permitindo a reconfiguração dos usos do solo, que não conta com a presença de arroios preservados em seus cursos naturais, revelando a opção estritamente econômica no trato com o meio ambiente na produção do espaço urbano da cidade de Ponta Grossa-PR.

Os elementos que conduzem a essa conclusão se assentam, primeiro, no fato de a legislação de zoneamento, uso e ocupação do solo nunca ter sido atualizada conforme as 
diretrizes da legislação federal, o Estatuto da Cidade, e do plano diretor municipal que data do ano de 2006. Ora, a legislação em questão data do ano de 1999 e desde então vêm sendo anualmente alterada para reconfigurar os zoneamentos das diferentes áreas da cidade, impactando sobremaneira na malha hídrica urbana, porquanto a maioria dos arroios urbanos estão canalizados, o que permite, em abstrato, uma intensa atividade do setor imobiliário em locais antes impossibilitados.

Por outro lado, os instrumentos legais de proteção aos arroios frente ao movimento do setor imobiliário não são aplicados ou ainda não foram regulamentados, como é o caso do Zoneamento Ambiental Municipal, cujas disposições deveriam nortear a construção de empreendimentos na cidade.

Essa dinâmica constatada nestes aspectos específicos das políticas públicas ambiental e urbana da cidade de Ponta Grossa-PR remetem à reflexão de Giovanni (2009), pois expressam realmente uma forma contemporânea de exercício do poder, revelando que, na conjuntura ponta-grossense a correlação de forças no trato das questões ambientais na produção do espaço urbano pende para uma atenção prioritária aos interesses do capital imobiliário e não do meio ambiente na proteção dos arroios urbanos, refletindo, assim, no desenvolvimento urbano da cidade, na medida em que as ações do planejamento urbano municipal atuam em sentido contrário à legislação federal em vigor e, assim, transformam o espaço urbano sem garantir a equilibrada proteção ambiental de seus recursos hídricos.

E, por fim, refletindo com Souza (2006) sobre o fato de as políticas públicas serem ações intencionais com objetivos definidos a serem alcançados e que devem ser pensadas em longo prazo, além de envolverem processos subsequentes à sua proposição, envolvendo ações estratégicas para sua implementação, execução e avaliação, é que urge a necessidade de o município de Ponta Grossa-PR realinhar suas estratégias de proteção ambiental, regulamentando os instrumentos previstos na legislação federal e aplicando-os dentro de uma perspectiva de planejamento urbano que integre e equalize o uso do solo com a proteção ambiental da cidade.

\section{Referências}

BOBBIO, Norberto. A era dos direitos. 22. ed. Rio de Janeiro: Campus, 2004.

BRASIL. [Constituição (1988)]. Constituição da República Federativa do Brasil. Brasília: Senado Federal, 1988. 
CARVALHO, Silvia Méri. O diagnóstico físico-conservacionista: DFC como subsídio à gestão ambiental da bacia hidrográfica do rio Quebra-Perna, Ponta Grossa - PR. 2004. 183 p. Tese (Doutorado em Geografia) - Universidade Estadual Paulista, Presidente Prudente, 2004.

CHAVES, Niltonci Batista et al. (org.). Visões de Ponta Grossa. Ponta Grossa: Ed. UEPG, 2001.

GIOVANNI, Geraldo di. As estruturas elementares das políticas públicas. Caderno de Pesquisa, Campinas, n. 82, 2009.

GOMES, Romeu. A análise de dados em pesquisa qualitativa. In: MINAYO, Maria Cecília de Souza (org.). Pesquisa social: teoria, método e criatividade. Petrópolis: Vozes, 1998.

HARVEY, David. Do gerenciamento ao empresariamento: a transformação da administração urbana no capitalismo tardio. Espaço \& Debates, São Paulo, n. 39, 1996. Disponível em: https://edisciplinas.usp.br/pluginfile.php/4401954/mod_resource/content/1/Harvey_Do\%2 Ogerenciamento\%20ao\%20empresariamento\%20\%281\%29.pdf. Acesso em: 20 nov. 2018.

IBGE - INSTITUTO BRASILEIRO DE GEOGRAFIA E ESTATÍ́STICA. Censo demográfico 2010. In: IBGE. Rio de Janeiro, 2010. Disponível em:

https://ww2.ibge.gov.br/home/estatistica/populacao/censo2010/default_atlas.shtm. Acesso em: 30 mar. 2019.

IBGE - INSTITUTO BRASILEIRO DE GEOGRAFIA E ESTATÍ́STICA. População estimada 2018. In: IBGE. Rio de Janeiro, 2018. Disponível em: https://cidades.ibge.gov.br/brasil/pr/pontaGrossa-panorama/panorama. Acesso em: 20 mar. 2019.

IBGE - INSTITUTO BRASILEIRO DE GEOGRAFIA E ESTATÍSTICA. Regiões de influência das cidades 2007. Rio de Janeiro: IBGE, 2008. Disponível em:

http://www.mma.gov.br/estruturas/PZEE/_arquivos/regic_28.pdf. Acesso em: 20 mar. 2019.

KAUCHAKJE, Samira; SCHEFFER, Sandra Maria. Políticas públicas sociais: a cidade e a habitação em questão. Curitiba: Intersaberes, 2017.

LEFEBVRE, Henri. Espaço e Política. Belo Horizonte: UFMG, 2008.

MEDEIROS, Carla Valéria; MELLO, Mário Sérgio de. Processos erosivos no espaço urbano de Ponta Grossa. In: DITZEL, Carmencita de Holleben Mello; SAHR, Cicilian Luiza Löwen (org.). Espaço e cultura: Ponta Grossa os Campos Gerais. Ponta Grossa: EDUEPG, 2001.

MONTE-MÓR, Roberto Luís de Melo. O cotidiano e a produção do espaço. [Belo Horizonte: UFMG], 2006. Disponível em:

http://www.mom.arq.ufmg.br/mom/02_eventos/coloquio2006/palestras/monte-mor.htm. Acesso em: 7 fev. 2019

PAULA, Jose Carlos Milléo de. População, poder local e qualidade de vida no contexto urbano de Ponta Grossa - PR. 1993. 192 f. Dissertação (Mestrado em Geografia) - Universidade Estadual Paulista, Rio Claro, 1993.

PONTA GROSSA. Decreto no 11.319, de 13 de abril de 2016. Aprova o Regimento Interno do Conselho Municipal da Cidade. Ponta Grossa: Câmara Municipal, 2016a. 
PONTA GROSSA. Decreto no 12.951, de 27 de abril de 2017. Regulamenta a análise do Estudo de Impacto de Vizinhança e do Relatório de Impacto de Vizinhança, e dá outras providências. Ponta Grossa: Câmara Municipal, 2017a.

PONTA GROSSA. Lei municipal no 11.233, de 27 de dezembro de 2012. Dispõe sobre a política ambiental municipal de Ponta Grossa e dá outras providências. Ponta Grossa: Câmara Municipal, 2016.

PONTA GROSSA. Lei municipal no 12.223, de 29 de julho de 2015. Institui o Conselho Municipal da Cidade. Ponta Grossa: Câmara Municipal, 2015.

PONTA GROSSA. Lei municipal no 12.821, de 8 de junho de 2017. Cria o Fundo Municipal de Desenvolvimento Urbano - FMDU, e dá outras providências. Ponta Grossa: Câmara Municipal, 2017b.

PONTA GROSSA. Lei municipal no 6.180, de 22 de junho de 1999. Cria o Instituto de Pesquisa e Planejamento Urbano de Ponta Grossa - IPLAN. Ponta Grossa: Câmara Municipal, 1999a.

PONTA GROSSA. Lei municipal no 6.329, de 16 de dezembro de 1999. Consolida e atualiza a legislação que dispõe sobre o zoneamento de uso e ocupação do solo das áreas urbanas do município de ponta grossa. Ponta Grossa: Câmara Municipal, 1999b.

PONTA GROSSA. Lei municipal no 8.663, de 9 de outubro de 2006. Atualiza a lei do plano diretor do município de ponta grossa em consonância com as novas diretrizes da revisão do plano diretor e dá outras providências. Ponta Grossa: Câmara Municipal, 2006.

PONTA GROSSA. Lei ordinária no 12.447, de 14 de março 2016. Dispõe sobre o Estudo de Impacto de Vizinhança - EIV e sobre o Relatório de Impacto de Vizinhança - RIVI, conforme especifica. Ponta Grossa: Câmara Municipal, 2016b.

PONTA GROSSA. Revisão do Plano Diretor Participativo. Ponta Grossa: IPLAN, 2016c.

ROGALSKI, Sérgio Ricardo. Índice de degradação ambiental da bacia hidrográfica do arroio Olarias, em Ponta Grossa-PR, entre 1980 e 2005. 2011. 145 f. Dissertação (Mestrado em Geografia) - Universidade Estadual de Ponta Grossa, Ponta Grossa, 2011.

SANTOS, Milton. Metamorfose do espaço habitado. 2. ed. São Paulo: Hucitec, 1991.

SANTOS, Milton. Por uma economia política da cidade: o caso de São Paulo. São Paulo: EdUSP, 2012.

SAUER, Mariane; RIBEIRO, Edalea Maria. Meio ambiente e serviço social: desafios ao exercício profissional. Textos \& Contextos, Porto Alegre, v. 11, n. 2, p. 390-398, 2012.

SCHEFFER, Sandra Maria. A construção do espaço local por políticas nacionais de habitação: o Programa Minha Casa Minha Vida em Ponta Grossa. 2017. Tese (Doutorado em Gestão Urbana) - Pontifícia Universidade Católica, Curitiba, 2017. 
SILVA, Thiago Luiz Bohatch da. Os arroios no processo de urbanização de Ponta Grossa - PR (1900 - 1950). 2017. 118 f. Dissertação (Mestrado em História) - Universidade Estadual de Ponta Grossa, Ponta Grossa, 2017.

SOUZA, Celina. Políticas públicas: uma revisão de literatura. Sociologias, Porto Alegre, v. 8, n. 16, p. 20-45, jul./dez. 2006. 